\title{
The expression of cystathionine gamma-lyase is regulated by estrogen receptor alpha in human osteoblasts
}

\author{
Elisabetta Lambertini ${ }^{1}$, Letizia Penolazzi ${ }^{1}$, Marco Angelozzi ${ }^{1}$, Francesco Grassi $^{2}$, \\ Laura Gambari ${ }^{2}$, Gina Lisignoli ${ }^{3}$, Pasquale De Bonis ${ }^{4}$, Michele Cavallo ${ }^{4}$ and Roberta \\ Piva $^{1}$ \\ ${ }^{1}$ Department of Biomedical and Specialty Surgical Sciences, University of Ferrara, Ferrara, Italy \\ ${ }^{2}$ Ramses Laboratory, Rizzoli Orthopedic Institute, Bologna, Italy \\ ${ }^{3}$ Laboratory of Immunorheumatology and Tissue Regeneration, Rizzoli Orthopedic Institute, Bologna, Italy \\ ${ }^{4}$ Department of Neurosurgery, S. Anna University Hospital, Ferrara, Italy \\ Correspondence to: Roberta Piva, email: piv@unife.it \\ Keywords: cystathionine gamma-lyase; $\mathrm{H}_{2} \mathrm{~S}$; osteoblasts; bone; estrogen receptor alpha \\ Received: July 12, $2017 \quad$ Accepted: September 04, $2017 \quad$ Published: October 04, 2017 \\ Copyright: Lambertini et al. This is an open-access article distributed under the terms of the Creative Commons Attribution License \\ 3.0 (CC BY 3.0), which permits unrestricted use, distribution, and reproduction in any medium, provided the original author and \\ source are credited.
}

\section{ABSTRACT}

Hydrogen sulfide $\left(\mathrm{H}_{2} \mathrm{~S}\right)$, generated in the osteoblasts predominantly via cystathionine-y-lyase (CSE), is bone protective. Previous studies suggested that the onset of bone loss due to estrogen deficiency is associated to decreased levels of $\mathrm{H}_{2} \mathrm{~S}$ and blunted gene expression of CSE. However, there are still a lot of unknowns on how $\mathrm{H}_{2} \mathrm{~S}$ levels influence bone cells function. The present study aims to explore the mechanisms by which estrogen may regulate CSE expression, in particular the role of estrogen receptor alpha (ERo) in human osteoblasts (hOBs). Vertebral lamina derived hOBs were characterized and then assessed for CSE expression by western blot analysis in the presence or absence of ER $\alpha$ overexpression. Bioinformatic analysis, luciferase reporter assay and ChIP assay were performed to investigate ERo recruitment and activity on hCSE gene promoter.

Three putative half Estrogen Responsive Elements (EREs) were identified in the hCSE core promoter and were found to participate in the ER $\alpha$ - mediated positive regulation of CSE expression. All osteoblast samples responded to ER $\alpha$ over-expression increasing the levels of CSE protein in a comparable manner. Notably, the ERa recruitment on the regulatory regions of the CSE promoter occurred predominantly in female hOBs than in male hOBs. The obtained results suggest that $\mathrm{CSE} / \mathrm{H}_{2} \mathrm{~S}$ system is in relation with estrogen signaling in bone in a gender specific manner.

\section{INTRODUCTION}

Cystathionine gamma-lyase (CSE) is the predominant hydrogen sulfide $\left(\mathrm{H}_{2} \mathrm{~S}\right)$-producing enzyme in mammalian cells although other systems including that supported by cystathionine $\beta$-synthase (CBS) exist [1]

The interest in the CSE enzyme and its regulation is growing, due to the recently described functions of $\mathrm{H}_{2} \mathrm{~S}$ including the S-sulphydration of various target proteins [2]. $\mathrm{H}_{2} \mathrm{~S}$ is a highly diffusible gasotransmitter, that influences cellular and organ functions by different mechanisms, including cross-interactions with other signaling pathways not yet fully elucidated [3]. The antioxidant and anti-inflammatory properties together with the cytoprotective effects of $\mathrm{H}_{2} \mathrm{~S}$ seem to be so critical that abnormal $\mathrm{H}_{2} \mathrm{~S}$ metabolism has been linked to several human pathologies, including autoimmune diseases, Alzheimer's, hypertension, coronary heart disease, atherosclerosis, cataracts, pancreatitis, type 1 diabetes, osteoporosis and rheumatoid arthritis [3-6]. It is therefore 
urgent to understand the tissue-dependent control of its production.

In the recent years, many factors have been discovered regulating CSE expression and activity in mouse and human, at transcriptional, posttranscriptional and post-translational levels [7]. Several compounds, including butyrate, specific hormones, calcium, streptozotocin (STZ), nitric oxide (NO), lipopolysaccharides (LPS), ovalbumin (OVA), pyridoxal5'-phosphate (PLP), vitamin D, S-propargyl-cysteine, and various $\mathrm{H}_{2} \mathrm{~S}$ donors, have been described as positive modulators of CSE activity and $\mathrm{H}_{2} \mathrm{~S}$ production [7-10]. In contrast, glucose, heme oxygenase-1/carbon monoxide (HO-1/CO) system, and various CSE inhibitors suppress CSE activity and, consequently, $\mathrm{H}_{2} \mathrm{~S}$ production $[11,12]$.

For what concerns pathophysiological conditions of the bone, CSE- $\mathrm{H}_{2} \mathrm{~S}$ was found as a dominant $\mathrm{H}_{2} \mathrm{~S}$ generation system in osteoblasts promoting osteoblast activity by the pathway of the calcium channel [13] and osteogenic master regulator Runx2 [14]. In particular, sulfhydrated Runx2 enhanced its transactivation and increased osteoblast differentiation and maturation, thereby promoting bone healing [14]. CSE expression is up-regulated during in vitro osteogenic process and is positively correlated with the mineral matrix deposition [15]. Conversely, decreased serum levels of $\mathrm{H}_{2} \mathrm{~S}$ together a decrease of CSE expression was recently found in mice with osteoporosis caused by estrogen deficiency [16].

However, whether the $\mathrm{H}_{2} \mathrm{~S}$ biosynthesis system in bone context is directly regulated by estrogen via its receptor action has not been clearly examined. To test the hypothesis that estrogen protects from bone loss [17] through CSE up-regulation in osteoblasts, we investigated whether the estrogen receptor alpha $(E R \alpha)$ directly participates in the regulation of CSE gene promoter activity and in the modulation of CSE expression in human male and female osteoblasts.

\section{RESULTS}

\section{Characterization of osteoblasts from human vertebral lamina bone}

The cells used in the experiments were obtained from human vertebral lamina bone fragments and are defined hereafter as human primary osteoblasts (hOBs) based on the below described characteristics.

Cells migrating out of the bone chips were grown until confluent, trypsinized, counted, and passaged. Analysis for the expression of bone markers was performed on cells from passage 2 (P2), cultured in nonosteogenic medium. The morphology of adherent cells was analyzed by fluorescence microscopy after staining of cytoskeletal F-actin filaments. As shown in Figure 1A, the cells exhibited an abundant thin F-actin filament meshwork typical for mature osteoblasts [18]. Mature osteoblast phenotype was verified by analyzing the expression of the osteogenic markers including alkaline phosphatase (ALP), Runx2 transcription factor belonging to Runt-related factors family, osteopontin (OPN), and Collagen type I (COL1). As shown in Figure 1B-1E, the cells spontaneously expressed ALP which is among the first functional genes expressed in the process of mineralization [19], Runx 2 which is essential in regulating the expression of the principal osteoblast-specific genes [20], OPN which is one of the abundant non-collagenous proteins in bone matrix [21], and COL1, the most abundant protein in bone [22].

Moreover, cells were positively immunostained for estrogen receptor alpha $(\mathrm{ER} \alpha)$ in both cytoplasmic and nucler compartment, but showed only a faint nuclear positivity for estrogen receptor beta $(\mathrm{ER} \beta)$ (Figure 1F, $1 G)$. The ability of cells to deposit mineralized matrix was evaluated in osteogenic cell culture medium; interestingly, after few days the cells formed the typical osteogenic clusters, and were strongly stained by Alizarin Red already at day 10 of culture (Figure $1 \mathrm{H}$ ).

Based on the measured parameters, the cell population from vertebral lamina includes bona fide mature osteoblasts.

\section{ER $\alpha$ affects CSE expression}

We then evaluated the CSE expression level on each sample distinguishing male from female. As reported in Figure 2A, all samples regardless of gender, expressed CSE at comparable levels.

When hOBs were transfected with ER $\alpha$ expression

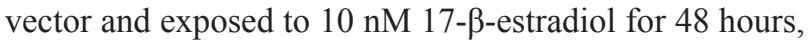
a remarkable increase of CSE protein expression was observed in both female and male cells (Figure 2B). These data suggest that ER $\alpha$ exerts a positive effect on the entire CSE transcriptional unit and its action may be so strong that it predominates over that of other regulatory factors and mechanisms.

Increased expression levels of ER $\alpha$ and CSE resulted also in a significant upregulation of osteoprotegerin (OPG) in all samples analyzed (Figure 2B). Several studies have indicated that estrogen stimulates OPG expression in osteoblast cells at transcriptional level through ER $\alpha$ [23]. A recent paper on human periodontal ligament cells (hPDLCs), proposed that $\mathrm{H}_{2} \mathrm{~S}$ could promote osteogenic differentiation by regulating OPG, since increased OPG expression was found after exogenous $\mathrm{H}_{2} \mathrm{~S}$ treatment [24]. To the best of our knowledge, the present study is the first reporting a positive correlation between CSE and OPG expression in human osteoblasts, suggesting that estrogenmediated OPG increase may be due both to a direct action of estrogen/ER $\alpha$ complex on OPG gene promoter, and to an increase of endogenous $\mathrm{H}_{2} \mathrm{~S}$ production. 


\section{Potential estrogen responsive elements in the hCSE core promoter}

The bioinformatic search for potential ER binding sites (Estrogen Responsive Elements, EREs) (Patch 1.0 and AliBaba 2.1 public software) in the hCSE core promoter $(-592 /+139)$ did not return any canonical consensus cis-elements. However, three putative half EREs were found at positions $-564,-414$, and -300 , together with few other validated transcription factor binding sites (Figure 3). Since it has been described that $E R \alpha$ can regulate the transcription of genes that contain ERE half-sites in their promoters [25], we focused our attention on these three half EREs.

\section{$\mathrm{ER} \alpha$ regulates hCSE promoter activity}

To determine whether the three half EREs in the hCSE core promoter could be responsible for mediating its activity, and to analyze the functional involvement of $\mathrm{ER} \alpha$ in the regulation of hCSE expression, we generated a luciferase reporter construct, cloning the hCSE core promoter upstream of firefly luciferase gene (LUC) in the pGL3-Basic vector (pGL3-731).

The analysis showed that the construct displayed an activity about 15 times higher than pGL3-Basic control vector in three out four analyzed samples, suggesting that it would contain some important cis-acting elements (Figure 4). When hOBs were co-transfected with pSG5HEO hER $\alpha$ expression vector in the presence of 10

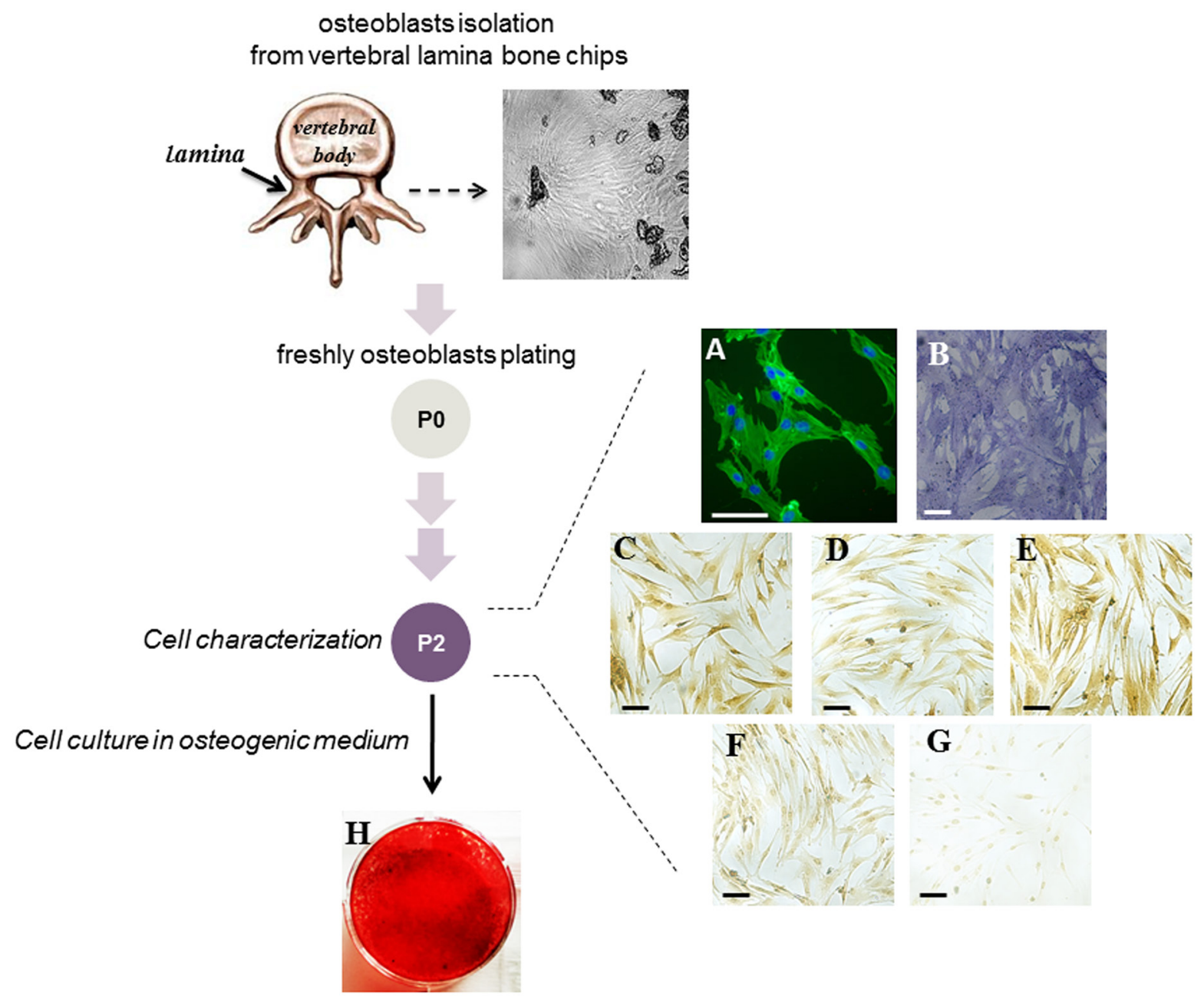

Figure 1: Characterization of the cells obtained from vertebral lamina bone chips. A scheme of the experimental approach is reported. A representative image of bone fragments obtained from vertebral lamina bone is shown. The cells (hOBs) were analyzed at P2 passage of culture. Cell-associated green fluorescence reveals actin cytoskeleton (Alexa Fluor 488-conjugated phalloidin); blue fluorescence indicates cell nuclei (DAPI DNA staining) (A). The analysis of ALP activity by specific staining (B) and the expression of RUNX2 (C), OPN (D), Collagen type I (E), ER $\alpha(\mathbf{F})$ and ER $\beta(\mathbf{G})$ by immunocytochemistry is reported. The ability of cells to deposit mineralized matrix was evaluated after 10 days of culture in osteogenic medium by Alizarin Red staining $(\mathbf{H})$. Bars correspond to $50 \mu \mathrm{m}$. 
nM 17- $\beta$-estradiol, they were differently susceptible to $\mathrm{ER} \alpha$ overexpression. Specifically, ER $\alpha$ overexpression deeply enhanced CSE promoter activity in female hOBs but not in male hOBs. On the contrary, exogenous Sp1 overexpression (data not shown) as well as estrogen exposure alone did not significantly alter the promoter activity in hOBs.

These results suggest that gender specific coregulators molecules may exist, and that the susceptibility to regulation by estrogen in hOBs depends on pathways that are different in male and female.

\section{ER $\alpha$ is in vivo recruited to hCSE promoter}

The in vivo binding of ER $\alpha$ to hCSE gene promoter was next investigated. For this purpose ChIP assay was performed by using specific primers that amplify the identified potential ER $\alpha$ binding sites in the 304 bp region $(-348 /-44)$ and 244 bp region (-592/-348) (Figure 5). This analysis revealed, for the first time, the ER $\alpha$ recruitment to the proximal region of hCSE promoter. Interestingly, in support of our hypothesis, ER $\alpha$ was stronger recruited in female hOBs than in male hOBs. The Sp1 binding previously described [8] was confirmed in three out four samples analyzed.

\section{DISCUSSION}

$\mathrm{H}_{2} \mathrm{~S}$ is a highly reactive molecule and, being a gas, it cannot be stored in vesicles or other biological compartments. As a consequence, the transcriptional regulation of $\mathrm{H}_{2} \mathrm{~S}$-producing enzymes is a key limiting step in the control of $\mathrm{H}_{2} \mathrm{~S}$ bioavailability [2]. $\mathrm{H}_{2} \mathrm{~S}$ is predominately and primarily produced by three enzymatic pathways, which include cystathionine $\beta$-syntase (CBS), cystathionine $\gamma$-lyase (CSE) and 3-mercaptopyruvate sulfur transferase (3-MST) [1-5]. CSE is the most studied being the predominant $\mathrm{H}_{2} \mathrm{~S}$-producing enzyme in mammalian cells [2].

Many recent papers attribute an important role to $\mathrm{H}_{2} \mathrm{~S}$ levels in the bone microenvironment [13-16, 26], and suggest a therapeutic potential of $\mathrm{H}_{2} \mathrm{~S}$ against bone loss caused by estrogen deficiency [16]. It has been demonstrated that $\mathrm{H}_{2} \mathrm{~S}$ levels decrease in aging [27] and
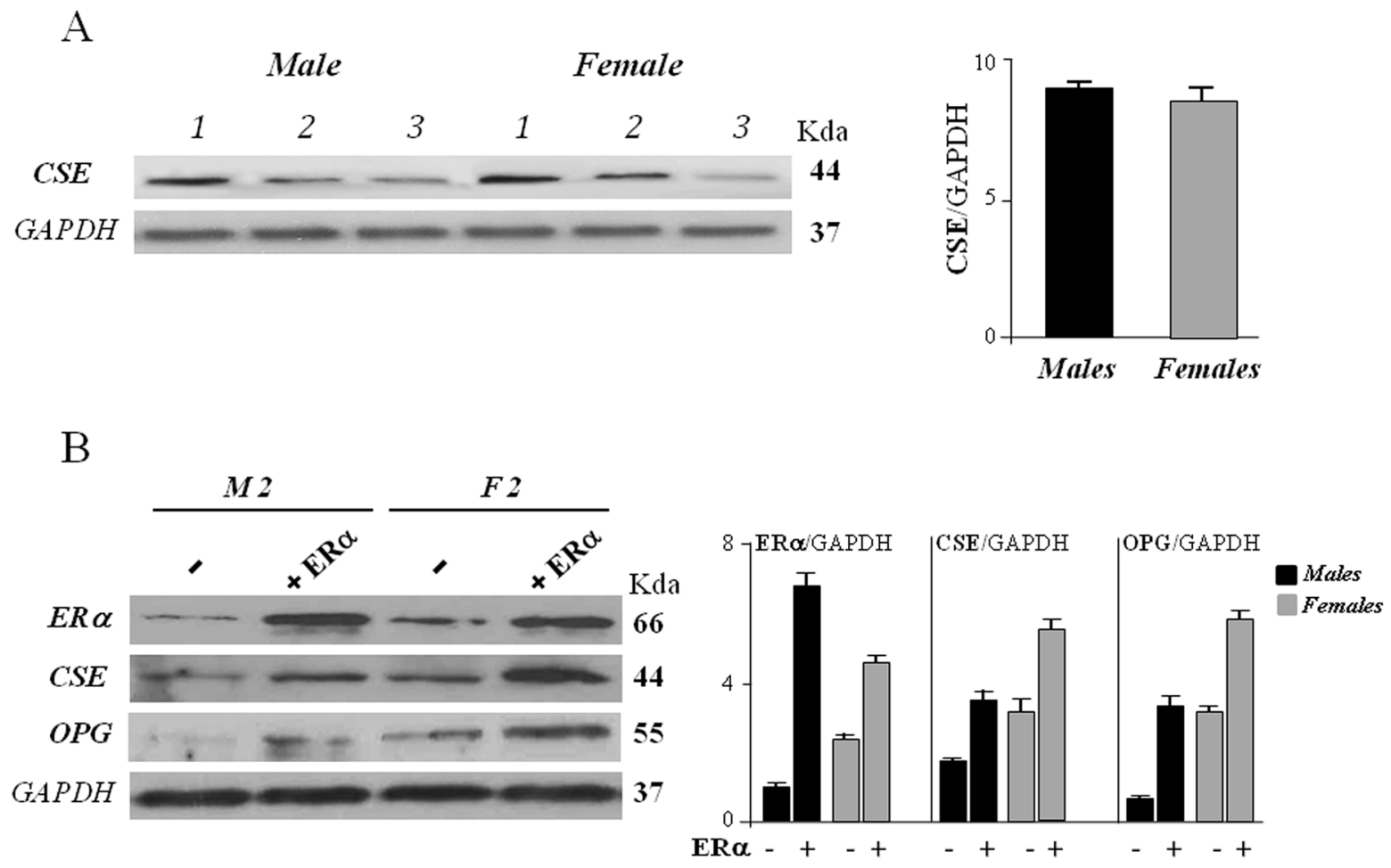

Figure 2: CSE protein expression in hOBs from male (M) and female (F) donors. (A) The cells were harvested after 72 hours of culture and subjected to Western blot analysis for CSE expression. Bar graphs show the densitometric analysis of all samples analyzed. GAPDH expression was used as the internal control to evaluate total protein of samples loaded, data were expressed as ratio of CSE in respect to GAPDH and presented as mean + standard deviation, $\mathrm{SD}$ ( $\mathrm{n}=3$ for male group, $\mathrm{n}=3$ for female group). (B) The cells were exposed to ER $\alpha$ overexpression together $10 \mathrm{nM} 17 \beta$-estradiol for 48 hours (+ ER $\alpha$ ) or remained untreated (-) and subjected to Western blot analysis for ER $\alpha, \mathrm{CSE}$ and OPG expression. Representative Western blot is reported (sample 2, M2, for male group, and sample 2, F2, for female group). Bar graphs show the densitometric analysis of all samples analyzed. GAPDH expression was used as the internal control to evaluate total protein of samples loaded, data were expressed as ratio of ER $\alpha$, CSE and OPG in respect to GAPDH and presented as mean + standard deviation, $\mathrm{SD}$ ( $\mathrm{n}=3$ for male group, $\mathrm{n}=3$ for female group). 


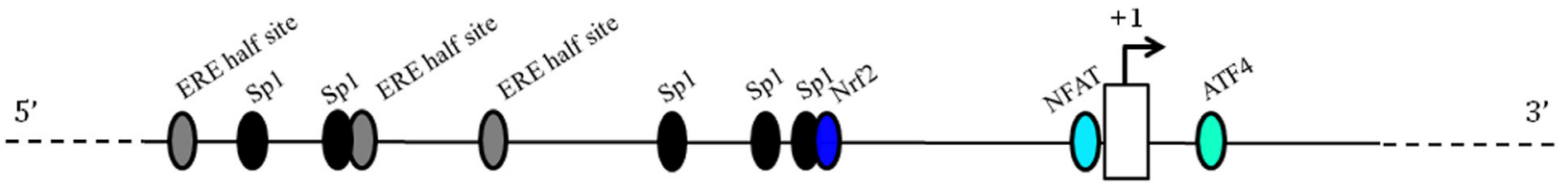

Figure 3: Schematic representation of the 5'-flanking region of the human CSE gene. The transcription factors up to now identified as regulators of CSE transcription are reported as ovals. Putative Estrogen Receptor binding sites are indicated as ERE half sites. Nrf2 (nuclear factor E2-related factor 2, involved in the antioxidant cell response), ATF4 (activating transcription factor 4, binds the cAMP response element), NFAT (the calcium-regulated nuclear factor of activated T cells) and Sp1 (specificity protein 1, an important component of the eukaryotic cellular transcriptional machinery) binding sites are indicated.
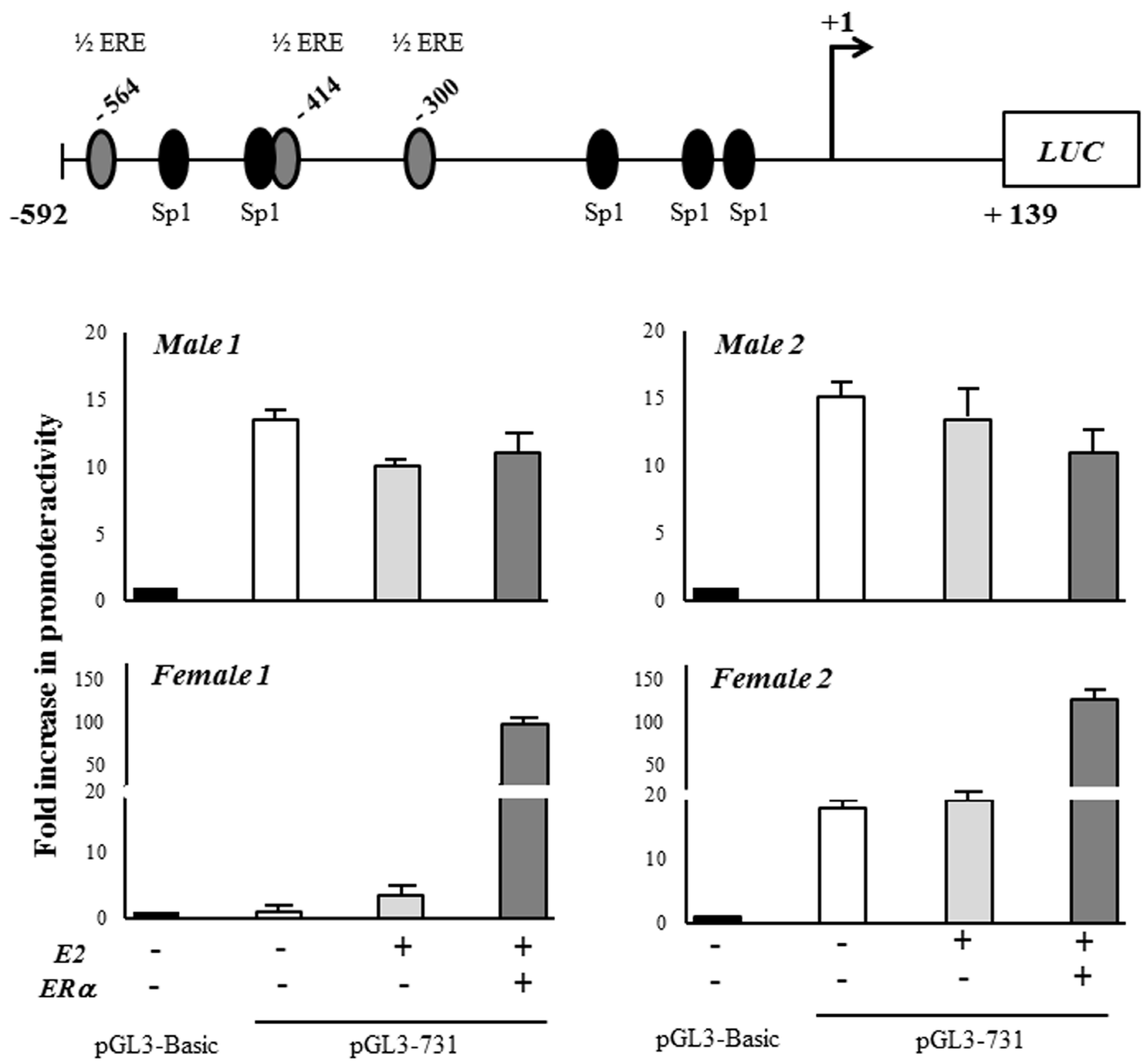

Figure 4: CSE gene promoter activity. The core promoter of CSE gene (-592/+139) was cloned into the upstream of firefly luciferase gene (LUC) in the pGL3-Basic vector (pGL3-731). The transfection was performed in hOB samples from two male and two female donors in absence (-) or in presence (+) of ER $\alpha$ expression vector together $10 \mathrm{nM} 17-\beta$-estradiol (E2) for 48 hours. The transfection efficiency was normalized by measuring the total protein in the extracts. The LUC output was normalized against the promoterless pGL3-Basic vector. Results are expressed as mean + SD. 
$\mathrm{H}_{2} \mathrm{~S}$-deficient mice displayed an osteoporotic phenotype, which could be rescued by treatment with donor of $\mathrm{H}_{2} \mathrm{~S}$ [13]. $\mathrm{H}_{2} \mathrm{~S}$ protects osteoblastic cells from $\mathrm{H}_{2} \mathrm{O}_{2}$-induced cell injury [28], mitigates bone loss in rat with spinal cord injury [29], and has beneficial effect on bone formation in patients affected by periodontitis [30]. $\mathrm{H}_{2} \mathrm{~S}$ is also able to regulate osteoblastogenesis and is relevant for the acquisition and preservation of bone mass controlling bone marrow stromal cells function by regulating $\mathrm{Ca}^{2+}$ influx $[13,16]$.

These studies, together the evidence that bone loss induced by estrogen deficiency in ovariectomized mice may be prevented by pharmacological restoration of normal $\mathrm{H}_{2} \mathrm{~S}$ levels [16], relate $\mathrm{H}_{2} \mathrm{~S}$ biosynthesis with estrogen signaling, however without providing any evidence of direct molecular interactions with enzymes producing $\mathrm{H}_{2} \mathrm{~S}$ in bone.

In the present study, for the first time, we demonstrated that estrogen receptor alpha $(E R \alpha)$ directly participates in the regulation of CSE promoter activity and CSE protein expression in human osteoblasts.
Importantly, all osteoblast samples responded to ER $\alpha$ over-expression increasing the levels of CSE protein in a comparable manner. However, the ER $\alpha$ recruitment on the regulatory regions of the CSE promoter occurred predominantly in female hOBs. This is in agreement with many evidences showing that ER signaling is not a core osteogenic pathway by itself, but regulates an array of osteogenic modulators including, in this case, potential gender specific co-regulators that provide correct $\mathrm{H}_{2} \mathrm{~S}$ levels. Therefore, the present paper open the way to new studies focusing on $\mathrm{H}_{2} \mathrm{~S}$ target proteins [31] that may also act as ER $\alpha$ partners. Hypothetical candidates may be sulfhydrated transcription factors or chromatin remodeling enzymes capable to differently modulate antioxidant, antiapoptotic and cytoprotective programs since they are differently sensitive to a gender specific microenvironment.

This hypothesis linked to the wide modulation of the $\mathrm{H}_{2} \mathrm{~S}$ signaling comes from a series of observations that demonstrate how many factors have been discovered to regulate CSE expression and activity at multiple levels,
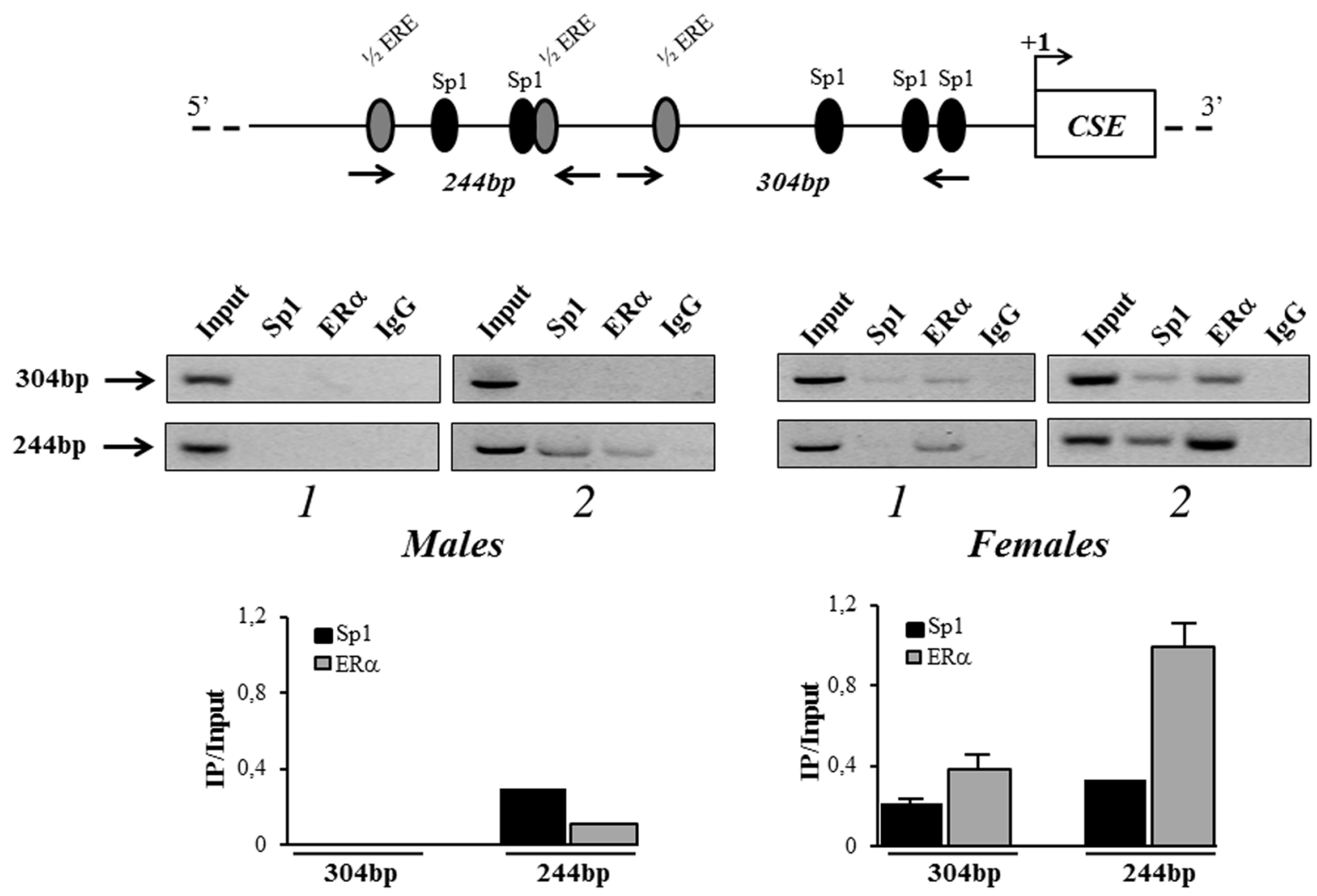

Figure 5: in vivo recruitment of ER $\alpha$ to CSE gene promoter. Protein-DNA complexes were in vivo formaldehyde cross-linked in hOBs from male and female donors and subjected to Chromatin immunoprecipitation (ChIP) analysis. Chromatin fragments were subjected to immunoprecipitation with antibodies against hER $\alpha$ or hSp1. After cross-link reversal, the co-immunoprecipitated DNA was detected by semi-quantitative PCR using the primer pairs spanning the proximal 304 bp region (-348/-44) and 244 bp region (-592/-348) on the CSE core promoter. Aliquots of chromatin taken before immunoprecipitation were used as input positive controls, whereas the negative control was the IgG immunoprecipitation. For each sample, levels of recruited ER $\alpha$ or Sp1 in the immunoprecipitates were determined by densitometry of the PCR fragments relative to Input control. Data are presented as mean + SD. 
including transcriptional, post-transcriptional and posttranslational levels. It is worth noting that up to now a small number of transcription factors, including Sp1, Nrf2, ATF4, Elk1 and NFAT, has been demonstrated to regulate CSE transcription through direct or indirect binding with CSE promoter [8, 32, 10, 33, 34]. miR-21 and miR-22 are reported to suppress but $\mathrm{PI} 3 \mathrm{~K}$ and TNF- $\alpha$ stimulate CSE transcription by targeting Sp1 gene [35-37]. A recent paper investigating $\mathrm{H}_{2} \mathrm{~S}$-microRNA crosstalk in cardiovascular diseases and estrogenic cardioprotection against oxidative stress, demonstrated that estrogen activates ER $\alpha$, which binds to Sp1 increasing CSE production in murine cardiomyocytes [9]. ER $\alpha$ also inhibits miR-22 which may also inhibit $\mathrm{ER} \alpha$, providing a secondary pathway for reducing CSE expression [35]. $\mathrm{H}_{2} \mathrm{O}_{2}$ and PDGF-BB induce CSE transcription by targeting Nrf2 [38].

Moreover, $\mathrm{CSE} / \mathrm{H}_{2} \mathrm{~S}$ system can be activated by compounds such as butyrate, specific hormones, calcium, streptozotocin, nitric oxide, lipopolysaccharide, ovalbumin, pyridoxal-5'-phosphate, vitamin D, S-propargyl-cysteine, and various $\mathrm{H}_{2} \mathrm{~S}$ donors [7-10]. In contrast, glucose, $\mathrm{HO}-1 / \mathrm{CO}$ system, and various $\mathrm{CSE}$ inhibitors are shown to suppress $\mathrm{CSE} / \mathrm{H}_{2} \mathrm{~S}$ system $[11,12]$.

Even if there are still a lot of unknowns on how $\mathrm{H}_{2} \mathrm{~S}$ levels influence cell function, however all these evidences suggest that crosstalk between $\mathrm{H}_{2} \mathrm{~S}$ and other signaling pathways may vary in a context-dependent manner and may have different roles in different disease conditions. Therefore, in relation to future perspectives for $\mathrm{H}_{2} \mathrm{~S}$ as a therapeutic agent, it is urgent to clarify how $\mathrm{H}_{2} \mathrm{~S}$ levels are regulated in the different tissues.

Considering that many of the estrogen regulated genes in osteoblasts are dependent on membrane ER $\alpha$ signaling [39], it remains to be explored how cross-talk between membrane and nuclear ER $\alpha$ signaling may influence $\mathrm{CSE} / \mathrm{H}_{2} \mathrm{~S}$ system.

Again, it is noteworthy another aspect regarding the importance of $\mathrm{CSE} / \mathrm{H}_{2} \mathrm{~S}$ system in the bone context, namely in bone tissue engineering. It has in fact been recently demonstrated that cells exposed to $\mathrm{H}_{2} \mathrm{~S}$ have potential applications in regenerative medicine, since modulation of $\mathrm{H}_{2} \mathrm{~S}$ metabolism may serve as a therapeutic approach to promote the viability of transplanted mesenchymal stem cells (MSCs) and facilitate MSC-based regeneration $[40,41]$.

In conclusion and in line with all evidences here reported, we speculated that factors influencing CSE expression and $\mathrm{H}_{2} \mathrm{~S}$ signaling (including estrogens themselves) become important for the development of strategies for bone protection and healing, in particular in women. Therefore, the understanding of gender-related $\mathrm{H}_{2} \mathrm{~S}$ biosynthesis might be an interesting challenge for the gender medicine field, to evaluate the perspectives of pharmacological enhancement or inhibition of CSE activity, as a strategy for new drug design in the bone female pathological context [42].

\section{MATERIALS AND METHODS}

\section{Isolation and culture of human osteoblasts}

Human bone fragments (explants) from vertebral lamina, discarded from spinal surgery were obtained from 6 patients ( 3 males and 3 females) using research protocol approved by Ethics Committee of the University of Ferrara and S. Anna Hospital (protocol approved on November 17, 2016). Patients' ages were between 53 and 73 years (mean age 63 years). Bone chips were dissected into smaller pieces and plated in T-25 culture flasks (Sarstedt, Nümbrecht, Germany) in 50\% DMEM high-glucose/50\% DMEM F-12/ 20\% Fetal Calf Serum (FCS) (Euroclone S.p.A., Milan, Italy), supplemented with $1 \mathrm{mM}$ L-Glutamine, antibiotics (penicillin $100 \mu \mathrm{g} / \mathrm{mL}$ and streptomycin $10 \mu \mathrm{g} / \mathrm{mL}$ ) (Sigma Aldrich, St. Louis, USA). Upon detection of a cell colony from the bone fragments, the cells were expanded until confluent (passage zero, $\mathrm{P} 0)$. Then the cells were harvested after treatment with $0.05 \%$ trypsin ethylenediamine tetraacetic acid (EDTA; Sigma-Aldrich), washed, counted by hemocytometric analysis, and used for further in vitro experiments. During the culture period, cells were incubated at $37^{\circ} \mathrm{C}$ in a humidified atmosphere of $5 \% \mathrm{CO}_{2}$ and the medium was changed every 3 or 4 days. hOBs (P2) were characterized for the presence of alkaline phosphatase activity (ALP Leukocyte kit cat. no. 86R; Sigma-Aldrich); for analysis of F-actin organization, cells were fixed with 4\% PFA (paraformaldehyde) for $30 \mathrm{~min}$, permeabilized with $0.1 \%$ Triton X-100 for $10 \mathrm{~min}$, and stained with Alexa Fluor-488 phalloidin (cat.no. sc-363791, Santa Cruz Biotechnology, Dallas, USA) in a phosphate-buffered saline (PBS) solution. For osteogenic induction, hOBs were cultured up to 21 days in osteogenic medium consisting in DMEM high-glucose $10 \%$ FCS, supplemented with $10 \mathrm{mM}$ $\beta$-glycerophosphate, $10^{-7} \mathrm{M}$ dexamethasone and $100 \mu \mathrm{M}$ ascorbate (Sigma-Aldrich). The extent of mineralized matrix in the plate was determined by Alizarin Red S staining (ARS; cat. no. A5533, Sigma-Aldrich). The cells were then fixed in $70 \%$ methanol for $1 \mathrm{~h}$ at room temperature, washed with PBS, stained with 40 mM ARS ( $\mathrm{pH} 4.2$ ) for $10 \mathrm{~min}$ at room temperature, washed five times with deionized water, and incubated in PBS for 15 min to eliminate non-specific staining. The stained matrix was observed at different magnifications using a Leitz microscope.

\section{Immunocytochemistry}

Immunocytochemistry was performer by using the ImmPRESS (cat.no. MP-7500, Vector Labs, Burlingame, USA). hOBs were fixed in cold $100 \%$ methanol and permeabilized with $0.2 \%(\mathrm{v} / \mathrm{v})$ Triton $\mathrm{X}-100$ in TBS (Tris-Buffered Saline) 1X. After blocking with serum, polyclonal antibodies for OPN (LF-123), COL1A1 (H-197 
\#sc-28657), Runx2 (M-70 \#sc-10758), ER $\alpha$ (G-20 \# sc544), or ER $\beta$ (H-150 \#sc-8974) (rabbit antihuman, 1:200 dilution, Santa Cruz Biotechnology), were added and incubated overnight $\left(4^{\circ} \mathrm{C}\right)$. Cells were then incubated in Vectastain ABC (Vector Labs) reagent $30 \mathrm{~min}$ and stained with DAB solution (cat.no. SK-4105, Vector Labs). After washing, cells were mounted in glycerol and observed with the use of the Nikon Eclipse 50i optical microscope.

\section{ER $\alpha$ overexpression}

For transfection experiments, the cells were plated in 6-well plates and maintained in phenol-red free DMEM containing 10\% charcoal stripped FCS, and were transiently transfected with $2.5 \mu \mathrm{g}$ of pSG5HEO (the wild-type human ER $\alpha$ expression vector) using LipofectamineTM 2000 transfection reagent (Thermo Fisher Scientific, Waltham, USA) in the presence of 10 nM 17- $\beta$-estradiol (Sigma-Aldrich). $48 \mathrm{~h}$ post transfection, cells were harvested and lysed for Western blot analysis.

\section{Western blots}

Details of the Western blot analysis were described previously [43]. Briefly, $20 \mu \mathrm{g}$ of each sample were electrophoresed on a $12 \%$ SDS-polyacrylamide gel. The proteins were then transferred onto PVDF membrane (Millipore, Billerica, USA). After blocking with PBS$0.05 \%$ Tween 20 and 5\% BSA (Sigma-Aldrich), the membrane was probed with the following antibodies: CSE (mouse anti-human, 1:1000 dilution, cat.no. H00001491-M03, Abnova, Taipei, Taiwan), ER $\alpha$ (rabbit anti-human, 1:1000 dilution, cat.no. sc-543, Santa Cruz Biotechnology), OPG (rabbit anti-human, 1:200 dilution, cat.no. sc-11383, Santa Cruz Biotechnology) and GAPDH (mouse anti-human, 1:5000 dilution, cat.no. MA1-16783, Thermo Fischer Scientific). After washing with PBSTween 20, the membranes were incubated with peroxidaseconjugated anti-mouse or anti-rabbit secondary antibody (Dako, Glostrup, Denmark). Immunocomplexes were detected using Immobilon Western Chemiluminescent HRP Substrate (Millipore). GAPDH was used to confirm equal protein loading. Densitometric analysis was performed by ImageJ software (NIH, USA, public domain available at: http://rsb.info.nih.gov/nih-image).

\section{In silico analysis of CSE promoter}

The prediction of estrogen responsive elements and $\mathrm{Sp} 1$ transcription factor binding sites in the CSE 5'-flanking region spanning +139 to -592 was performed using Patch 1.0 and AliBaba 2.1 public software. The bioinformatic analysis of CSE promoter region failed to identify canonical ERE sites but found three ERE halfsites and confirmed five $\mathrm{Sp} 1$ consensus sites already previously described [8].

\section{Plasmid construct}

A 731 bp fragment containing the 5'-flanking region of the human CSE gene $(-592$ to +139$)$ was generated by PCR using human genomic DNA of human HEK293 cells as template. The PCR product was digested with XhoI and HindIII (Promega, Madison, USA) and subsequently cloned into the promoterless pGL3 Basic vector containing a firefly luciferase cDNA (Promega), generating the pGL3-731 construct.

\section{Transfection and luciferase reporter assay}

For each experiment, $4 \times 10^{4}$ hOBs were seeded into 24-well plates in $500 \mu \mathrm{L}$ phenol red-free DMEM containing $10 \%$ charcoal stripped FCS. The cells were cultured for 48 hours and then co-transfected with 0.5 $\mu \mathrm{g}$ of the reporter construct and $0.25 \mu \mathrm{g}$ of pSG5HEO using Lipofectamine 2000 Reagent, according to the manufacturer's instructions. 24 hours after transfection, the medium was replaced with fresh phenol red-free medium and stimulated, where required, with $10 \mathrm{nM}$ 17 - $\beta$-estradiol for another 24 hours. Cells were then washed once with PBS and lysed in $120 \mu \mathrm{L}$ of $1 \mathrm{X}$ passive lysis buffer (Promega). The luciferase activity was measured using the Luciferase Assay System (Promega) in a GloMax 20/20 single tube Luminometer (Promega) and corrected for total protein content.

For fold change, the luciferase output was normalized against the promoterless pGL3-Basic vector, arbitrarily defined as 1 . For each hOB sample all transfections were performed in triplicate, and data were presented as mean values with standard deviation.

\section{Chromatin immunoprecipitation (ChIP)}

ChIP was conducted as previously described [44]. ChIP assay was performed using a ChIP Assay Kit (cat. no. 17-295 Upstate, USA) following the manufacturer's instructions. After cross linking, chromatin was fixed with $1 \%$ formaldehyde at $37^{\circ} \mathrm{C}$ for $10 \mathrm{~min}$, cells were washed with cold PBS, scraped, collected on ice, lysed and sonicated. An equal amount of chromatin was immunoprecipitated at $4{ }^{\circ} \mathrm{C}$ overnight with $5 \mu \mathrm{g}$ of the following ChIP grade antibodies: ER $\alpha$ \#sc-543X, Sp1 \#sc-14027, or non-specific IgG \#sc-2027X (Santa Cruz Biotechnology). Immunoprecipitated products were collected after incubation with Protein A-agarose beads. The beads were washed, and the bound chromatin was eluted in ChIP eluition buffer. The samples were incubated at $65^{\circ} \mathrm{C}$ overnight to reverse the cross linking. The proteins were then digested with Proteinase $\mathrm{K}$ for 1 $\mathrm{h}$ at $45^{\circ} \mathrm{C}$ and DNA was purified in $50 \mu \mathrm{L}$ of Tris-EDTA with a PCR purification kit (Qiagen, Hilden, Germany) according to the manufacturer's instructions. The DNA precipitates and Input ( $2 \%$ of total chromatin used for the immunoprecipitation) were further subjected to semi- 
quantitative PCR using specific primers pairs spanned the proximal $304 \mathrm{bp}$ region (-348/-44) and $244 \mathrm{bp}$ region $(-592 /-348)$ on the CSE core promoter. PCR products were analyzed by agarose gel electrophoresis and visualized by UV light apparatus. Densitometric analysis was performed by ImageJ software.

\section{Statistical analysis}

Data are presented as mean values with standard deviation from at least three replicates for each sample.

\section{Abbreviations}

CBS: cystathionine $\beta$-synthase; CSE: cystathionine $\gamma$-lyase; ChIP: chromatin immunoprecipitation; GAPDH: glyceraldehyde 3-phosphate dehydrogenase; ER: estrogen receptor; EREs: estrogen responsive elements; hOBs: human osteoblasts; $\mathrm{H}_{2} \mathrm{~S}$ : hydrogen sulfide; $\mathrm{Sp} 1$ : specificity protein 1

\section{Author contributions}

EL was involved in study design, performed the majority of the laboratory work, contributed to the analysis of data and writing of the manuscript; LP was involved in study design and data interpretation; MA was responsible for osteoblasts isolation and contributed to the analysis of data; FG, LG, and GL were involved in study design; PdB and $\mathrm{MC}$ were responsible for bone specimens and study design; RP was responsible for study design, analysis of data and manuscript writing.

\section{CONFLICTS OF INTEREST}

The authors have no conflicts of interest to declare.

\section{FUNDING}

This work was supported by funding from the Ministero della Salute, Grant Ricerca Finalizzata \# PE2011-02348395, and FAR 2016.

\section{REFERENCES}

1. Kabil O, Banerjee R. Enzymology of $\mathrm{H}_{2} \mathrm{~S}$ biogenesis, decay and signaling. Antioxid Redox Signal. 2014;20:770-782.

2. Rose $\mathrm{P}$, Moore $\mathrm{PK}, \mathrm{Zhu} \mathrm{YZ}$. $\mathrm{H}_{2} \mathrm{~S}$ biosynthesis and catabolism: new insights from molecular studies. Cell Mol Life Sci. 2017;74:1391-1412.

3. Sen N. Functional and molecular insights of hydrogen sulfide signaling and protein sulfhydration. J Mol Biol. 2017;429:543-561.

4. Predmore BL, Lefer DJ, Gojon G. Hydrogen sulfide in biochemistry and medicine. Antioxidants \& Redox Signaling. 2012;17:119-140.
5. Stein A, Bailey SM. Redox biology of hydrogen sulfide: implications for physiology, pathophysiology, and pharmacology. Redox Biol. 2013;1:32-39.

6. Wallace JL, Wang R. Hydrogen sulfide-based therapeutics: exploiting a unique but ubiquitous gasotransmitter. Nat Rev Drug Discov. 2015;14:329-345.

7. Zhao K, Li H, Li S, Yang G. Regulation of cystathionine gamma-lyase $/ \mathrm{H}_{2} \mathrm{~S}$ system and its pathological implication. Front Biosci. 2014;19:1355-1369.

8. Yang G, Pei Y, Teng H, Cao Q, Wang R. Specificity protein-1 as a critical regulator of human cystathionine gamma-lyase in smooth muscle cells. J Biol Chem. 2011;286:26450-26460.

9. Wang L, Tang ZP, Zhao W, Cong BH, Lu JQ, Tang XL, Li XH, Zhu XY, Ni X. MiR-22/Sp-1 links estrogens with the up-regulation of cystathionine $\gamma$-lyase in myocardium, which contributes to estrogenic cardioprotection against oxidative stress. Endocrinology. 2015;156:2124-2137.

10. Mistry RK, Murray TV, Prysyazhna O, Martin D, Burgoyne JR, Santos C, Eaton P, Shah AM, Brewer AC. Transcriptional regulation of cystathionine- $\gamma$-lyase in endothelial cells by NADPH oxidase 4-dependent signaling. J Biol Chem. 2016;291:1774-1788.

11. Manna P, Gungor N, McVie R, Jain SK. Decreased cystathionine- $\gamma$-lyase (CSE) activity in livers of type 1 diabetic rats and peripheral blood mononuclear cells (PBMC) of type 1 diabetic patients. J Biol Chem. 2014;289:11767-11778.

12. Qingyou Z, Junbao D, Weijin Z, Hui Y, Chaoshu T, Chunyu Z. Impact of hydrogen sulfide on carbon monoxide/ heme oxygenase pathway in the pathogenesis of hypoxic pulmonary hypertension. Biochem Biophys Res Commun. 2004;317:30-37.

13. Liu Y, Yang R, Liu X, Zhou Y, Qu C, Kikuiri T, Wang S, Zandi E, Du J, Ambudkar IS, Shi S. Hydrogen sulfide maintains mesenchymal stem cell function and bone homeostasis via regulation of $\mathrm{Ca}(2+)$ channel sulfhydration. Cell Stem Cell. 2014; 15:66-78.

14. Zheng Y, Liao F, Lin X, Zheng F, Fan J, Cui Q, Yang J, Geng B, Cai J. Cystathionine $\gamma$-lyase-hydrogen sulfide induces runt-related transcription factor 2 sulfhydration, thereby increasing osteoblast activity to promote bone fracture healing. Antioxid Redox Signal. 2017;27:742-753.

15. Gambari L, Lisignoli G, Gabusi E, Manferdini C, Paolella F, Piacentini A, Grassi F. Distinctive expression pattern of cystathionine- $\beta$-synthase and cystathionine$\gamma$-lyase identifies mesenchymal stromal cells transition to mineralizing osteoblasts. J Cell Physiol. 2017;232:3574-3585.

16. Grassi F, Tyagi AM, Calvert JW, Gambari L, Walker LD, Yu M, Robinson J, Li JY, Lisignoli G, Vaccaro C, Adams J, Pacifici R. Hydrogen sulfide is a novel regulator of bone formation implicated in the bone loss induced by estrogen deficiency. J Bone Miner Res. 2016;31:949-963. 
17. Syed F, Khosla S. Mechanisms of sex steroid effects on bone. Biochem Biophys Res Commun. 2005;328:688-696.

18. Yourek G, Hussain MA, Mao JJ. Cytoskeletal changes of mesenchymal stem cells during differentiation. ASAIO J. 2007;53:219-228.

19. Sabokbar A, Millett PJ, Myer B, Rushton N. A rapid, quantitative assay for measuring alkaline phosphatase activity in osteoblastic cells in vitro. Bone Miner. 1994;27:57-67.

20. Lian JB, Stein GS, Javed A, van Wijnen AJ, Stein JL, Montecino M, Hassan MQ, Gaur T, Lengner CJ, Young DW. Networks and hubs for the transcriptional control of osteoblastogenesis. Rev Endocr Metab Disord. 2006;7:1-16.

21. Denhardt DT, Noda M. Osteopontin expression and function: Role in bone remodeling. J Cell Biochem. 1998; 30-31:92-102.

22. Ducy P, Schinke T, Karsenty G. The osteoblast: a sophisticated fibroblast under central surveillance. Science. 2000;289:1501-1504.

23. Hofbauer LC, Khosla S, Dunstan CR, Lacey DL, Spelsberg TC, Riggs BL. Estrogen stimulates gene expression and protein production of osteoprotegerin in human osteoblastic cells. Endocrinology. 1999;140:4367-4370.

24. Liao C, Hua Y. Effect of hydrogen sulphide on the expression of osteoprotegerin and receptor activator of NF- $\kappa B$ ligand in human periodontal ligament cells induced by tension-force stimulation. Arch Oral Biol. 2013;58:1784-1790.

25. Harrington WR, Sheng S, Barnett DH, Petz LN, Katzenellenbogen JA, Katzenellenbogen BS. Activities of estrogen receptor alpha- and beta-selective ligands at diverse estrogen responsive gene sites mediating transactivation or transrepression. Mol Cell Endocrinol. 2003;206:13-22.

26. Lv M, Liu Y, Xiao TH, Jiang W, Lin BW, Zhang XM, Lin YM, Xu ZS. GYY4137 stimulates osteoblastic cell proliferation and differentiation via an ERK1/2dependent anti-oxidant mechanism. Am J Transl Res. 2017;9:1183-1192.

27. Perridon BW, Leuvenink HGD, Hillebrands JL, van Goor $\mathrm{H}$, Bos EM. The role of hydrogen sulfide in aging and agerelated pathologies. Aging (Albany NY). 2016;8:22642289. https://doi.org/10.18632/aging.101026.

28. Xu ZS, Wang XY, Xiao DM, Hu LF, Lu M, Wu ZY, Bian JS. Hydrogen sulfide protects MC3T3-E1 osteoblastic cells against $\mathrm{H}_{2} \mathrm{O}_{2}$-induced oxidative damage-implications for the treatment of osteoporosis. Free Radic Biol Med. 2011; 50:1314-1323.

29. Yang X, Hao D, Zhang H, Liu B, Yang M, He B. Treatment with hydrogen sulfide attenuates sublesional skeletal deterioration following motor complete spinal cord injury in rats. Osteoporosis Int. 2017;28:687-695.

30. Greabu M, Totan A, Miricescu D, Radulescu R, Virlan J, Calenic B. Hydrogen sulfide, oxidative stress and periodontal diseases: a concise review. Antioxidants. 2016;5:2-13.

31. Gadalla MM, Snyder SH. Hydrogen sulfide as a gasotransmitter. J Neurochem. 2010;113:14-26.

32. Yang G, Zhao K, Ju Y, Mani S, Cao Q, Puukila S, Khaper N, Wu L, Wang R. Hydrogen sulfide protects against cellular senescence via S-sulfhydration of Keap1 and activation of Nrf2. Antioxid Redox Signal. 2013;18:1906-1919.

33. Taniguchi S, Kimura T, Umeki T, Kimura Y, Kimura H, Ishii I, Itoh N, Naito Y, Yamamoto H, Niki I. Protein phosphorylation involved in the gene expression of the hydrogen sulphide producing enzyme cystathionine gamma-lyase in the pancreatic $\beta$-cell. Mol Cell Endocrinol. 2012;350:31-38.

34. Gonzalez Bosc LV, Osmond JM, Giermakowska WK, Pace CE, Riggs JL, Jackson-Weaver O, Kanagy NL. NFAT regulation of cystathionine $\gamma$-lyase expression in endothelial cells is impaired in rats exposed to intermittent hypoxia. Am J Physiol Heart Circ Physiol. 2017;312:791-799.

35. Hackfort BT, Mishra PK. Emerging role of hydrogen sulfide-microRNA crosstalk in cardiovascular diseases. Am J Physiol Heart Circ Physiol. 2016;310:802-812.

36. Yang G, Pei Y, Cao Q, Wang R. MicroRNA-21 represses human cystathionine gamma-lyase expression by targeting at specificity protein-1 in smooth muscle cells. J Cell Physiol. 2012;227:3192-3200.

37. Yin P, Zhao C, Li Z, Mei C, Yao W, Liu Y, Li N, Qi J, Wang L, Shi Y, Qiu S, Fan J, Zha X. Sp1 is involved in regulation of cystathionine gamma-lyase gene expression and biological function by PI3K/Akt pathway in human hepatocellular carcinoma cell lines. Cell Signal. 2012;24:1229-1240.

38. Hassan MI, Boosen M, Schaefer L, Kozlowska J, Eisel F, von Knethen A, Beck M, Hemeida RA, El-Moselhy MA, Hamada FM, Beck KF, Pfeilschifter J. Platelet-derived growth factor-BB induces cystathionine $\gamma$-lyase expression in rat mesangial cells via a redox-dependent mechanism. $\mathrm{Br}$ J Pharmacol. 2012;166:2231-2242.

39. Gustafsson KL, Farman H, Henning P, Lionikaite V, Movérare-Skrtic S, Wu J, Ryberg H, Koskela A, Gustafsson JA, Tuukkanen J, Levin ER, Ohlsson C, Lagerquist MK. The role of membrane ER $\alpha$ signaling in bone and other major estrogen responsive tissues. Sci Rep. 2016;6:29473.

40. Yang R, Liu Y, Shi S. Hydrogen sulfide regulates homeostasis of mesenchymal stem cells and regulatory $\mathrm{T}$ cells. J Dent Res. 2016;95:1445-1451.

41. Zhang Q, Liu S, Li T, Yuan L, Liu H, Wang X, Wang F, Wang S, Hao A, Liu D, Wang Z. Preconditioning of bone marrow mesenchymal stem cells with hydrogen sulfide improves their therapeutic potential. Oncotarget. 2016;7:58089-58104. https://doi.org/10.18632/ oncotarget.11166.

42. Legato M, Editor. Principles of gender-specific medicine in the genomic era, 3rd edition. New York, NY: Academic Press; 2017. 
43. Torreggiani E, Lisignoli G, Manferdini C, Lambertini E, Penolazzi L, Vecchiatini R, Gabusi E, Chieco P, Facchini A, Gambari R, Piva R. Role of Slug transcription factor in human mesenchymal stem cells. J Cell Mol Med. 2012;16:740-751.
44. Lambertini E, Lisignoli G, Torreggiani E, Manferdini C, Gabusi E, Franceschetti T, Penolazzi L, Gambari R, Facchini A, Piva R. Slug gene expression supports human osteoblast maturation. Cell Mol Life Sci. 2009;66:3641-3653. 